\title{
Role of sulfation in thyroid hormone metabolism
}

\author{
Theo J. Visser \\ Department of Internal Medicine III, Erasmus University Medical School, P.O. Box 1738, Room Bd \\ 234, 3000 DR Rotterdam, The Netherlands
}

Received 11 September 1993; revision received 2 February 1994; accepted 19 February 1994

\begin{abstract}
The type $I$ iodothyronine deiodinase (ID-I) in liver and kidney converts the prohormone thyroxine $\left(\mathrm{T}_{4}\right)$ by outer ring deiodination (ORD) to bioactive 3,3',5-triiodothyronine $\left(\mathrm{T}_{3}\right)$ or by inner ring deiodination (IRD) to inactive 3,3',5-triiodothronine $\left(\mathrm{rT}_{3}\right)$, while it also catalyzes the IRD of $\mathrm{T}_{3}$ and the ORD of $\mathrm{rT}_{3}$, with the latter as the preferred substrate. Sulfation of the phenolic hydroxyl group blocks the ORD of $\mathrm{T}_{4}$, while it strongly stimulates the IRD of both $T_{4}$ and $T_{3}$, indicating that sulfation is an important step in the irreversible inactivation of thyroid hormone. This review summarizes recent studies concerning this interaction between sulfation and deiodination of iodothyronines, the characterization of iodothyronine sulfotransferase activities, the measurement of iodothyronine sulfates in humans and animals, and the possible physiological importance of iodothyronine sulfation.
\end{abstract}

Keywords: Thyroid hormone; Iodothyronines; Sulfation; Deiodination

Under normal conditions the prohormone thyroxine $\left(3,3^{\prime}, 5,5^{\prime}\right.$-tetraiodothyronine, $T_{4}$ ) is the predominant product secreted by the thyroid gland. $T_{4}$ is converted in peripheral tissues by outer ring deiodination (ORD) to the bioactive form of the thyroid hormone $3,3^{\prime}, 5$-triiodothyronine $\left(\mathrm{T}_{3}\right)$ or by inner ring deiodination (IRD) to the inactive metabolite $3,3^{\prime}, 5^{\prime}$-triiodothyronine (reverse $T_{3}, \mathrm{rT}_{3}$ ) (Fig. 1). Both $T_{3}$ and $\mathbf{r T}_{3}$ are further deiodinated to inactive products, especially $3,3^{\prime}-$ diiodothyronine $\left(3,3^{\prime}-\mathrm{T}_{2}\right)$, which is generated by IRD of $\mathrm{T}_{3}$ and by ORD of $\mathrm{rT}_{3}$ (Fig. 1). Thus, the bioactivity of the thyroid hormone is controlled by competing ORD (activation) and IRD (inactivation) pathways [1,2]. 


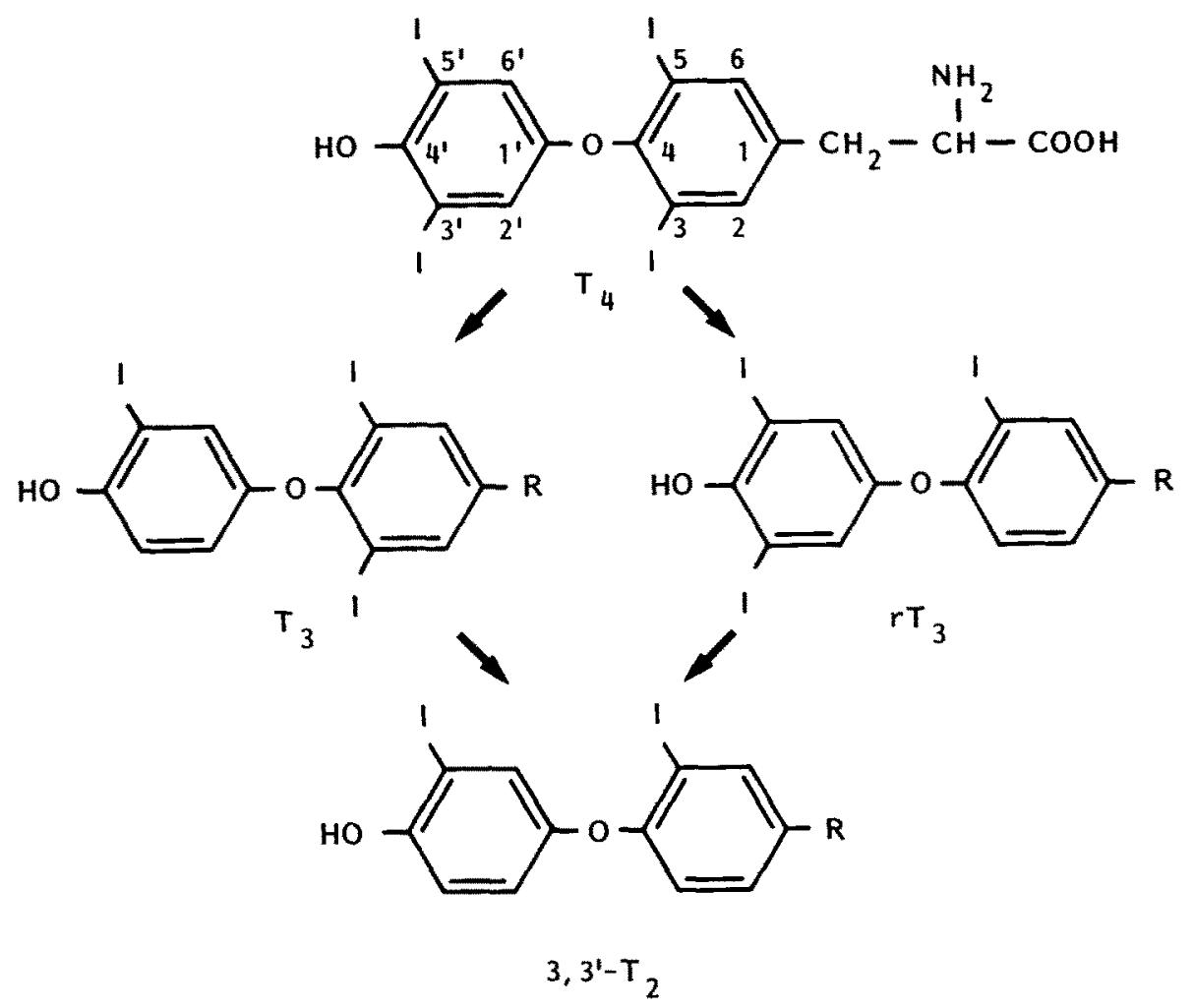

Fig. I. Stepwise deiodination of $T_{4}$ by ORD to $T_{3}$ and by IRD to $\mathrm{rT}_{3}$, and further by IRD of $T_{3}$ and ORD of $\mathrm{rT}_{3}$ to $3,3^{\prime}-\mathrm{T}_{2}$.

Besides deiodination, glucuronidation and sulfation of the phenolic hydroxyl group are other important pathways of iodothyronine metabolism [2,3]. The glucuronides are stable conjugates which are rapidly excreted in the bile [3]. However, the sulfates are rapidly deiodinated in the liver, and little of these conjugates is normally excreted intact in the bile or appears in the serum $[3,4]$. Sulfation strongly facilitates the IRD of $T_{4}$ and $T_{3}$, whereas the ORD of $T_{4}$ sulfate $\left(T_{4} S\right)$ is inhibited, suggesting that sulfate conjugation is a primary step leading to the irreversible inactivation of thyroid hormone.

\section{Sulfation of iodothyronines}

Although sulfation of $T_{3}$ and other iodothyronines in rats has been known for a long time, little work has been done to characterize the sulfotransferases (STs) involved until recently (for a review, see [5]). Sekura et al. [6] have tested the sulfation 
of a variety of iodothyronine derivatives by purified rat liver aryl sulfotransferase (AST) I and AST IV with an assay utilizing $100 \mu \mathrm{M}\left[{ }^{35}\right.$ S]PAPS and $50 \mu \mathrm{M}$ substrate. AST I and AST IV showed similar sulfation rates with $T_{3}$ but varying activities with other iodothyronines. The substrate preferences of these enzymes overlapped for some compounds (e.g. 3,3'- $T_{2}>T_{3}>r_{3}>T_{4}$, with $T_{4}$ sulfation being undetectable in both cases), but differed markedly for others (e.g. 3- $T_{1}$ and $\left.3^{\prime}-\mathrm{T}_{1}\right) . K_{\mathrm{m}}$ and $\mathrm{V}_{\max }$ values were not determined in this study [6].

With a standard assay utilizing $0.4 \mu \mathrm{M}\left[{ }^{35}\right.$ S]PAPS and $150 \mu \mathrm{M} \mathrm{T}$, Young et al. [7] have demonstrated that the hormone is a substrate for at least three phenol sulfotransferases (PSTs) in human tissues: two forms of thermostable (TS) PST and a thermolabile (TL) PST. Of these, TS PST is especially abundant in the liver, while TL PST is more prevalent in the intestine. In keeping with the prominent role of TS PST, $T_{3}$ sulfation in human liver was inhibited by low concentrations of 2,6dichloro-4-nitrophenol (DCNP; $\mathrm{IC}_{50} \approx 5 \mu \mathrm{M}$ ), a selective inhibitor of this isoenzyme [7]. Sulfate conjugation of $\mathrm{T}_{3}$ was also inhibited by $\mathrm{T}_{4}\left(\mathrm{IC}_{50} \approx 150 \mu \mathrm{M}\right)$, but sulfation of $\mathrm{T}_{4}$ was not tested. Reported $K_{\mathrm{m}}$ values amounted to $100-200 \mu \mathrm{M}$ for $\mathrm{T}_{3}$ and $0.1-0.4 \mu \mathrm{M}$ for PAPS with the different isolated isoenzymes as well as with crude human liver cytosol [7].

Gong et al. [8] have recently reported on the measurement of hepatic $T_{3}$ ST activity in different species with a method similar to that of Sekura et al. [6], employing $50 \mu \mathrm{M}$ substrate and $200 \mu \mathrm{M}\left[{ }^{35}\right.$ S]PAPS. A marked sex difference was found in rats, where $T_{3} S T$ activities were 2-5-fold higher in male than in female animals, which was related to the different growth hormone secretion patterns in males and females. The opposite was found in mice, in that $T_{3}$ sulfation rates were 5 -fold higher in female than in male animals, while no sex-related difference was found in human liver $\mathrm{T}_{3}$ ST activity [8]. In agreement with the results of Sekura et al. [6], using AST I and AST IV, iodothyronine sulfation rates in rat liver cytosol were in the order $\mathrm{T}_{3}>\mathrm{rT}_{3}>\mathrm{T}_{4}$; sulfation of $3,3^{\prime}-\mathrm{T}_{2}$ was not tested [8]. The involvement of an enzyme homologous to human TS PST was suggested by the finding that $T_{3}$ sulfation in rat liver cytosol is inhibited by low concentrations of DCNP $\left(\mathrm{IC}_{50} 5.5\right.$ $\mu \mathrm{M})$ and pentachlorophenol $\left(\mathrm{IC}_{50} 0.065 \mu \mathrm{M}\right)$ [8].

Hurd et al. [9] reported recently, in abstract form, on $T_{3}$ ST activities in different rat tissues using unspecified concentrations of unlabeled PAPS and $T_{3}$, measuring the production of $T_{3} S$ by specific radioimmunoassay. $T_{3}$ sulfation rates were highest in liver followed by brain and kidney. Hepatic $\mathrm{T}_{3} \mathrm{ST}$ activity was relatively heat stable, showing a $K_{\mathrm{m}}$ value for $\mathrm{T}_{3}$ of $114 \mu \mathrm{M}$.

In conclusion, sulfation of $\mathrm{T}_{3}$ and other iodothyronine derivatives is catalyzed by multiple PST isoenzymes in liver and other tissues in various species. Both in human and rat liver, $\mathrm{T}_{3}$ ST activity is associated largely with thermostable forms of PST which are sensitive to inhibition by DCNP. The higher rate of $T_{3}$ sulfation in male vs. female rats suggests that AST IV is a major $\mathrm{T}_{3}$ ST in rat liver. However, the contribution of different isoenzymes to the sulfation of $T_{3}$ and analogs both in humans and in rats remains to be established. It is remarkable that $T_{4}$ is a poor substrate for all ST activities studied so far. 


\section{Deiodination of iodothyronine sulfates}

Three thyroid hormone-deiodinating enzymes have been identified, of which the type I iodothyronine deiodinase (ID-I) is present in liver, kidney and thyroid [1,2]. It is a transmembrane selenoenzyme located in the endoplasmic reticulum of liver cells, which requires thiols such as dithiothreitol (DTT) as the cofactor, and has both ORD and IRD activity $[1,2,10]$. Although ID-I shows preference for $\mathrm{rT}_{3}$ as the substrate, its most important physiological purpose is the peripheral production of $\mathrm{T}_{3}$ from $\mathrm{T}_{4}$. The type II iodothyronine deiodinase (ID-II) is present predominantly in the brain, pituitary and brown adipose tissue [1,2]. ID-II has only ORD activity, and is an important enzyme for local intracellular $T_{3}$ production in these tissues. The type III iodothyronine deiodinase (ID-III) is also found in brain but also in skin and in the placenta [1,2]. It has only IRD activity and seems a major site for the degradation of $T_{4}$ and $T_{3}$.

Although $\mathrm{T}_{4}$ itself may be deiodinated by ID-I either in the outer ring to $\mathrm{T}_{3}$ or in the inner ring to $\mathrm{rT}_{3}$, this is changed dramatically after sulfate conjugation [11]. The IRD of $\mathrm{T}_{4} \mathrm{~S}$ is accelerated about 200 times due to a decrease in apparent $K_{\mathrm{m}}$ value as well as an increase in $\mathrm{V}_{\max }$ (Table 1). However, ORD of $\mathrm{T}_{4} \mathrm{~S}$ is undetectable, which excludes that $T_{4}$ is converted to $T_{3}$ by an alternative route via their sulfoconjugates.

ID-I deiodinates primarily the inner ring of $T_{3}$, a reaction which is also markedly stimulated by sulfoconjugation [12]. The facilitated IRD of $T_{3} S$ is characterized by $\mathrm{a} \sim 30$-fold increase in $\mathrm{V}_{\max }$ with little effect on the apparent $K_{\mathrm{m}}$ value (Table 1). We have observed similar effects of sulfation on the deiodination of $T_{3}$ by the type I deiodinase in human liver [13].

As mentioned above, $\mathrm{rT}_{3}$ is the preferred ID-I substrate; its ORD to $3,3^{\prime}-\mathrm{T}_{2}$ is catalyzed $>100$-fold more effectively than that of any other known non-sulfated

Table 1

Effects of sulfation on deiodination of iodothyronines by rat liver type I deiodinase

\begin{tabular}{llllcr}
\hline Substrate & Deiodination & Product & $K_{\mathrm{m}}$ & $\mathrm{V}_{\max }$ & $\mathrm{V}_{\max } / K_{\mathrm{m}}$ \\
\hline $\mathrm{T}_{4}$ & ORD & $\mathrm{T}_{3}$ & 2.3 & 30 & 13 \\
$\mathrm{~T}_{4} \mathrm{~S}$ & ORD & $\mathrm{T}_{3} \mathrm{~S}$ & & undetectable & \\
$\mathrm{T}_{4}$ & IRD & $\mathrm{rT}_{3}$ & 1.9 & 18 & 9 \\
$\mathrm{~T}_{4} \mathrm{~S}$ & IRD & $\mathrm{rT}_{3} \mathrm{~S}$ & 0.3 & 527 & 1817 \\
$\mathrm{~T}_{3}$ & IRD & $3,3^{\prime}-\mathrm{T}_{2}$ & 6.2 & 36 & 6 \\
$\mathrm{~T}_{3} \mathrm{~S}$ & IRD & $3,3^{\prime}-\mathrm{T}_{2} \mathrm{~S}$, & 4.6 & 1050 & 230 \\
$\mathrm{rT}_{3}$ & ORD & $3,3^{\prime}-\mathrm{T}_{2}$ & 0.06 & 559 & 8730 \\
$\mathrm{rT}_{3} \mathrm{~S}$ & ORD & $3,3^{\prime}-\mathrm{T}_{2} \mathrm{~S}$ & 0.06 & 516 & 8600 \\
$3,3^{\prime}-\mathrm{T}_{2}$ & ORD & $3-\mathrm{T}_{1}$ & 8.9 & 188 & 21 \\
$3,3^{\prime}-\mathrm{T}_{2} \mathrm{~S}$ & ORD & $3-\mathrm{T}_{1} \mathrm{~S}$ & 0.3 & 353 & 1040 \\
\hline
\end{tabular}

Kinetic parameters were determined using liver microsomes from euthyroid rats in $0.1 \mathrm{M}$ phosphate $(\mathrm{pH}$ 7.2), $2 \mathrm{mM}$ EDTA and 3-5 $\mathrm{mM}$ DTT. $K_{\mathrm{m}}$ is expressed in $\mu \mathrm{M}$ and $\mathrm{V}_{\max }$ in pmol/min per $\mathrm{mg}$ protein. Data are derived from Refs. [11-15]. 
iodothyronine [14]. It is remarkable that in contrast to the ORD of $\mathrm{T}_{4}$, which is blocked by sulfation, deiodination of $\mathrm{rT}_{3}$ is not affected [11], while ORD of $3,3^{\prime}-\mathrm{T}_{2}$ is even markedly stimulated by sulfate conjugation [15]. In the latter case this is associated with a major decrease in the apparent $K_{\mathrm{m}}$ value and a minor increase in $\mathrm{V}_{\max }($ Table 1$)$.

In conclusion, the effect of sulfation of iodothyronines on their deiodination by ID-I strongly depends on the structure of the substrate. Sulfation markedly facilitates the IRD of $T_{4}$ and $T_{3}$, while ORD is either inhibited $\left(T_{4}\right)$, unaffected $\left(\mathrm{rT}_{3}\right)$ or clearly stimulated $\left(3,3^{\prime}-\mathrm{T}_{2}\right)$ by sulfoconjugation. The mechanism by which sulfation stimulates the type I deiodination of the various substrates remains unclear. In some cases sulfation primarily effects an increase in $\mathrm{V}_{\max }$, in others there is a predominant decrease in the apparent $K_{\mathrm{m}}$ value. Since rat and human ID-I are basic proteins $[16,17]$, the facilitated deiodination of sulfated iodothyronines may be due to beneficial ionic interaction of the negatively charged sulfate group with protonated residues in the enzyme active center [4]. The effect of conjugation on iodothyronine deiodination depends both on the site and the nature of the conjugating group. Type I deiodination of different iodothyronines is moderately stimulated by sulfonation of the $\alpha \mathrm{NH} 2$ group of these compounds, yielding non-naturally occurring sulfamates, but this effect is much less pronounced than that of sulfation [18]. We have also found that ID-I does not catalyze the deiodination of glucuronidated iodothyronines [19]. Finally, the effects of sulfation appears specific for ID-I, since deiodination of sulfated substrates is not observed with either ID-II (unpublished work) or ID-III [20,21].

\section{Production of iodothyronine sulfates in hepatocytes and in vivo}

\section{1. $T_{3} S$}

Studies with isolated rat hepatocytes have indicated that $T_{3}$ is metabolized to roughly similar extents by three pathways [19]: (a) glucuronidation $\left(T_{3} \rightarrow T_{3} G\right)$; (b) IRD, rapidly followed by successive sulfation and $\mathrm{ORD}\left(\mathrm{T}_{3} \rightarrow 3,3^{\prime}-\mathrm{T}_{2} \rightarrow 3,3^{\prime}-\mathrm{T}_{2} \mathrm{~S}\right.$ $\left.\rightarrow \mathrm{I}^{-}\right)$; and (c) sulfation, rapidly followed by successive IRD and ORD $\left(\mathrm{T}_{3} \rightarrow \mathrm{T}_{3} \mathrm{~S}\right.$ $3,3^{\prime}-\mathrm{T}_{2} \mathrm{~S} \rightarrow \mathrm{I}^{-}$). Under normal conditions, therefore, $\mathrm{T}_{3} \mathrm{G}$ and iodide are the main labeled products produced from $\left[3^{\prime}-{ }^{125} \mathrm{I}\right] \mathrm{T}_{3}$. If the sulfotransferase capacity of the cells is inhibited by $\mathrm{SO}_{4}{ }^{2-}$ depletion or by addition of ST inhibitors, $\mathrm{I}^{-}$production is largely inhibited, and $3,3^{\prime}-T_{2}$ (and $3,3^{\prime}-T_{2} G$ ) accumulates. If on the other hand ID-I activity is inhibited with 6-propyl-2-thiouracil (PTU) or with iopanoic acid (IOP), $\mathrm{I}^{-}$production is also decreased, but this is now accompanied by the accumulation of $\mathrm{T}_{3} \mathrm{~S}$ and $3,3^{\prime}-\mathrm{T}_{2} \mathrm{~S}[15,19,22]$.

After an intravenous (i.v.) injection of $\left[{ }^{125} \mathrm{I}_{3} \mathrm{~T}_{3}\right.$ to bile duct-cannulated rats, we found that $\left[{ }^{125} \mathrm{I}_{3} \mathrm{~T}_{3} \mathrm{G}\right.$ was the predominant radioactive product excreted in the bile [23]. Pretreatment of rats with PTU was found to have little effect on the biliary excretion of $T_{3} G$, but excretion of $T_{3} S$ and $3,3^{\prime}-T_{2} S$ was strongly increased [23]. While treatment of rats with DCNP had little effect on the biliary excretion of $T_{3}$ metabolites compared with untreated rats, DCNP greatly diminished the PTUinduced excretion of $\mathrm{T}_{3} \mathrm{~S}$ and $3,3^{\prime}-\mathrm{T}_{2} \mathrm{~S}$ [23]. This is in agreement with the above- 
mentioned in vitro findings, suggesting an important contribution of thermostable, DCNP-sensitive PSTs to hepatic $T_{3}$ sulfation.

$\mathrm{T}_{3} \mathrm{~S}$ is not only excreted in bile but, depending on the conditions, it may also be detected in blood. After i.v. administration of $\left[{ }^{125} \mathrm{I}\right] \mathrm{T}_{3}$ to untreated rats, iodide is the predominant radioactive metabolite detected in plasma. However, if labeled $\mathrm{T}_{3}$ is injected in PTU-treated rats, the appearance of iodide in plasma is strongly decreased, while $T_{3} S$ and $3,3^{\prime}-T_{2} S$ accumulate to levels that readily exceed serum $T_{3}$ levels [24]. However, PTU does not decrease plasma $T_{3}$ clearance. Following an i.v. injection of $\left[{ }^{125} \mathrm{I}\right] \mathrm{T}_{3} \mathrm{~S}$ to control rats, the conjugate is cleared from plasma more rapidly than $T_{3}$. Iodide is again the main metabolite observed in plasma, and $20 \%$ of the dose is excreted as intact $T_{3} S$ in the bile [24]. Plasma $T_{3} S$ clearance is strongly inhibited by PTU, which is associated with a marked decrease in plasma iodide appearance as well as with an increase in the biliary excretion of intact $\mathrm{T}_{3} \mathrm{~S}$ to $80 \%$ of the dose [24]. Therefore, the PTU-induced increase in plasma levels and biliary excretion of $T_{3} S$ after $T_{3}$ injection is explained by the inhibition of $T_{3} S$ deiodination rather than an increase in $T_{3}$ sulfation.

We have developed a radioimmunoassay (RIA) for the measurement of $T_{3} S$ in serum [25]. Although the antiserum employed in this RIA showed high affinity and relatively high specificity for $T_{3} S$, its significant cross-reactivity with $T_{3}$ and $T_{4}$ in combination with the high serum $\mathrm{T}_{4}$ levels necessitated the isolation of the serum iodothyronine conjugate fraction prior to the assay. In agreement with the abovementioned findings, RIA of serum $\mathrm{T}_{3} \mathrm{~S}$ showed low but detectable levels in normal rats, with a mean of $0.09 \mathrm{nM}$ vs. $1.3 \mathrm{nM}$ for $\mathrm{T}_{3}$ [26]. Serum $\mathrm{T}_{3} \mathrm{~S}$ markedly increased after treatment with PTU but not with methimazole, a thyrostatic drug that does not inhibit ID-I [26]. Results similar to those with PTU were obtained in animals treated with the X-ray contrast agent IOP that also inhibits ID-I [22]. The increase in serum $\mathrm{T}_{3} \mathrm{~S}$ by PTU or IOP occurred even though serum $\mathrm{T}_{3}$ was decreased, and was associated with a similar increase in serum $\mathrm{rT}_{3}[22,26]$.

Analysis of human serum with this RIA demonstrated that $T_{3} S$ levels in normal subjects were mostly undetectable, i.e. $<0.1 \mathrm{nM}$ vs. $2 \mathrm{nM}$ for $T_{3}$ [27]. Serum $\mathrm{T}_{3} \mathrm{~S}$ became barely detectable in healthy persons treated with $\mathrm{T}_{3}(1 \mu \mathrm{g} / \mathrm{kg}$ body wt./day), and showed an additional slight increase after administration of PTU, while serum $\mathrm{T}_{3} \mathrm{~S}$ levels increased markedly after administration of IOP [27]. The increases in serum $\mathrm{T}_{3} \mathrm{~S}$ induced by these regimens were strongly correlated with the increases in serum $\mathrm{rT}_{3}$, which is also largely cleared by type I deiodination, as serum $\mathrm{rT}_{3}$ also showed a much larger increase after IOP than after PTU treatment [27]. Data reported by LoPresti et al. [28] indicate that in normal humans $T_{3} S$ is cleared extremely rapidly from the circulation, and that this clearance is inhibited moderately by PTU administration but markedly by IOP administration as well as by fasting, another condition that may be associated with a decrease in hepatic ID-I activity [28].

The groups of Wu and Chopra have recently developed improved RIAs for $T_{3} S$, the much greater specificities of which obviate the need to prepurify the samples, so that they can be applied directly to ethanol extracts of serum [29]. Using this RIA, Chopra et al. [29] also noted that serum $\mathrm{T}_{3} \mathrm{~S}$ levels are low in normal subjects $(<0.1$ 
$\mathrm{nM}$ ), and that they increase significantly after treatment of patients with IOP [29]. They also found that the serum $T_{3} S / T_{3}$ ratio is decreased in hyperthyroid patients and strongly increased in hypothyroid patients, in patients with non-thyroidal illness and in newborns, as determined in fetal cord serum [29]. Hepatic ID-I activity is known to be impaired in hypothyroidism, non-thyroidal illness, and in the fetal stage, while enzyme activity is increased in hyperthyroidism [1,2]. Furthermore, extremely high $\mathrm{T}_{3} \mathrm{~S}$ levels have been detected by $\mathrm{Wu}$ et al. [30] in plasma, bile and meconium of fetal sheep (and in the allantoic fluid) at the time hepatic ID-I activity is still very low. Therefore, these recent data demonstrate that also in humans and sheep, $\mathrm{T}_{3} \mathrm{~S}$ levels accumulate to high levels, if deiodination of the conjugate by the type I deiodinase is inhibited.

\section{2. $T_{4} S$}

Although in vitro tests of $T_{4}$ as the substrate for tissue $S T$ activities have been largely negative, evidence has been reported that $T_{4}$ undergoes significant sulfation in liver. Sato et al. [31] noted that $T_{4}$ was metabolized in primary cultures of rat hepatocytes by deiodination and by conjugation. Under normal conditions, ORD and IRD were the predominant pathways of $\mathrm{T}_{4}$ metabolism. However, if deiodination was saturated at high substrate concentrations, conjugates were found to accumulate, including $\mathrm{T}_{4} \mathrm{~S}$ [31]. We have investigated the biliary excretion products of $\mathrm{T}_{4}$ after an i.v. injection of $\left[{ }^{125} \mathrm{I}_{\mathrm{T}} \mathrm{T}_{4}\right.$ to rats [32]. In control rats, $\mathrm{T}_{4} \mathrm{G}$ was the predominant radioactive compound in bile together with smaller amounts of $T_{3} G$, $\mathrm{rT}_{3} \mathrm{G}$ and $\mathrm{T}_{4} \mathrm{~S}$. Pretreatment with PTU resulted in an increase in biliary $\mathrm{T}_{4} \mathrm{G}$ parallel with the increased plasma $T_{4}$ retention, a marked decrease in $T_{3} G$ due to inhibited $T_{4}$ to $T_{3}$ conversion, a marked increase in $r T_{3} G$ due to inhibited degradation of $\mathrm{rT}_{3}$, and a large increase in $\mathrm{T}_{4} \mathrm{~S}$ excretion [32]. Despite the negligible tissue $\mathrm{T}_{4} \mathrm{ST}$ activities detected in vitro, these findings demonstrate that $\mathrm{T}_{4}$ undergoes significant sulfation in vivo, and that $T_{4} S$ is predominantly cleared by type $I$ deiodination.

Although $\mathrm{T}_{4} \mathrm{~S}$ is a significant biliary $\mathrm{T}_{4}$ metabolite in rats, we have not been able to detect this conjugate in serum after an i.v. injection of $\left[{ }^{125} I\right] \mathrm{T}_{4}$ even in PTUtreated rats [32]. Using very sensitive and specific RIAs for $\mathrm{T}_{4} \mathrm{~S}, \mathrm{Wu}$ et al. [33] and Chopra et al. [34] have recently reported on the measurement of low concentrations of $\mathrm{T}_{4} \mathrm{~S}$ in human serum. However, the mean $\mathrm{T}_{4} \mathrm{~S}$ levels in normal human subjects differed markedly between the two studies, i.e. 100 and 19 pM, respectively (vs. $\approx 100 \mathrm{nM}$ for $\mathrm{T}_{4}$ ). Compared with serum from normal adults, increased $\mathrm{T}_{4} \mathrm{~S}$ levels were observed in human amniotic fluid and in fetal cord serum obtained at the time of delivery [33,34]. Both groups also reported on an increase in serum $\mathrm{T}_{4} \mathrm{~S}$ after administration of IOP to hyperthyroid patients $[33,34]$. Remarkably high levels of $\mathrm{T}_{4} \mathrm{~S}$ were also detected in serum, bile and meconium of fetal sheep and in the allantoic fluid [30]. Together, these finding indicate that sulfation is a significant pathway for metabolism of $\mathrm{T}_{4}$ in humans, rats and sheep, and that the concentration of this conjugate in body fluids builds up in conditions with low ID-I activity.

\section{3. $r T_{3} S$}

We have found minor amounts of $\mathrm{rT}_{3} \mathrm{~S}$ (and $3,3^{\prime}-\mathrm{T}_{2} \mathrm{~S}$ ) after incubation of $\mathrm{rT}_{3}$ 
with isolated rat hepatocytes, and only if this is done in the presence of PTU [35]. Normally, type I ORD is the foremost pathway of $\mathrm{rT}_{3}$ metabolism in these cells. Although this converts $\mathrm{rT}_{3}$ to $3,3^{\prime}-\mathrm{T}_{2}$, little of the latter is normally observed, because it is rapidly further metabolized by successive sulfation and deiodination, as described above for hepatic $\mathrm{T}_{3}$ metabolism [35].

Recently, Wu et al. [36] have also reported on the measurement of $\mathrm{rT}_{3} \mathrm{~S}$ in human serum with a newly developed RIA for this sulfoconjugate. $\mathrm{rT}_{3} \mathrm{~S}$ concentrations were low (in normal human subjects, i.e. mean $40 \mathrm{pM}$ vs. $0.3 \mathrm{nM}$ for $\mathrm{rT}_{3}$, and no significant changes were noted in hypothyroid, hyperthyroid or pregnant subjects [36]. However, marked elevations were produced after administration of IOP to hyperthyroid patients [36]. Dramatic increases of $\mathrm{rT}_{3} \mathrm{~S}$ were observed in fetal cord serum relative to serum $\mathrm{rT}_{3} S$ in adults [36]. As mentioned above for $\mathrm{T}_{4} S$ and $\mathrm{T}_{3} \mathrm{~S}$, high $\mathrm{rT}_{3} \mathrm{~S}$ levels were also detected in serum, bile and meconium of fetal sheep and in the allantoic fluid [37]. Therefore, $\mathrm{rT}_{3}$ appears to be sulfated to some extent in humans and sheep, although this may be significant only if ID-I, the principal site of $\mathrm{rT}_{3}$ metabolism, is inhibited.

\section{Possible role of iodothyronine sulfation}

Sulfation is a way to inactivate thyroid hormone: $T_{3} S$ does not bind to the $T_{3}$ receptor and is devoid of thyromimetic activity in several cell systems $[38,39]$. Furthermore, not only $\mathrm{T}_{3} \mathrm{~S}$ but also $\mathrm{T}_{4} \mathrm{~S}$ is rapidly degraded by ID-I. It has been postulated that sulfation of iodothyronines has an important function when ID-I activity is impaired, such as in non-thyroidal illness and during fetal development $[20,21]$. Under these conditions, $T_{3} S$ is not degraded in tissues with normally high ID-I activity, while the hormone is also protected by sulfation against degradation by ID-III $[20,21]$. Active $\mathrm{T}_{3}$ may then be recovered from $\mathrm{T}_{3} \mathrm{~S}$ through the action of sulfatases in tissues where hormone action is required or by bacterial sulfatases in the intestine. We have indeed demonstrated that bacterial sulfatases are important for the resorption of $\mathrm{T}_{3}$ following biliary excretion of $\mathrm{T}_{3} \mathrm{~S}$ [40-42]. Furthermore, significant hydrolysis of $\mathrm{T}_{3} \mathrm{~S}$ has been detected in liver and brain microsomes in humans and rats [43]. Santini et al. [44] have recently observed thyromimetic effects after administration of $\mathrm{T}_{3} \mathrm{~S}$ to hypothyroid rats, with a potency of $\approx 20 \%$ of that of $T_{3}$, which appeared to be mediated by the liberation of $T_{3}$ from the injected $T_{3} S$. An interesting aspect of these findings is that the biological effects of administered $\mathrm{T}_{3} \mathrm{~S}$ in hypothyroid subjects are self-limited, since the initially impaired ID-I activity in hypothyroidism is restored during $\mathrm{T}_{3} \mathrm{~S}$ treatment, as is the deiodinative clearance of the conjugate [44]. However, the exact biological function of the different iodothyronine sulfates in particular during fetal development remains to be fully explored.

\section{Conclusions}

Different ST isoenzymes appear to be involved in humans and in rats with the sulfation of $\mathrm{T}_{3}$ and other iodothyronines. Under normal conditions, sulfation ac- 
celerates the deiodination of the inner ring of $\mathrm{T}_{4}$ and $\mathrm{T}_{3}$ by the type I deiodinase in liver and probably also in kidney, which results in the irreversible inactivation of the hormone. However, under conditions of low ID-I activity, significant amounts of $T_{3}$ may be recovered from $T_{3} S$ by sulfatases expressed in different tissues as well as by bacteria in the intestine. The former may be important for the generation of local $\mathrm{T}_{3}$ in tissues where active hormone is required, while the bacterial sulfatases are essential in the supply of systemic $\mathrm{T}_{3}$. Much further work remains to be done, however, to explore the potential role of $T_{3} S$ as a reservoir from which active $T_{3}$ is released when and where the active thyroid hormone is required.

\section{Acknowledgement}

Financial support was provided by the Commission of the European Communities (contract BMH1-CT92-0097, Biomedical and Health Research Program).

\section{References}

1 T.J. Visser, Metabolism of thyroid hormone, in: B.A. Cooke, R.J.B. King and H.J. van der Molen (Eds.), Hormones and Their Actions, Part I, Elsevier, Amsterdam, 1988, pp. 81-103.

2 J. Köhrle, R.D. Hesch and J.L. Leonard, Intracellular pathways of iodothyronine metabolism, in: L.E. Braverman and R.D. Utiger (Eds.), The Thyroid, Lippincott, Philadelphia, 1991, pp. 144-189.

3 T.J. Visser, Importance of deiodination and conjugation in the hepatic metabolism of thyroid hormone, in: M.A. Greer (Ed.), The Thyroid Gland, Raven Press, New York, 1990, pp. 255-283.

4 T.J. Visser, J.C.J. van Buuren, M. Rutgers, S.J. Eelkman Rooda and W.W de Herder, The role of sulfation in thyroid hormone metabolism, Trends Endocrinol. Metab., 1 (1990) 211-218.

5 R.J. Anderson, Biochemical characterization of triiodothyronine sulfotransferase, in: S.Y. Wu and T.J. Visser (Eds.), Thyroid Hormone Metabolism: Molecular Biology and Alternate Pathways, CRC Press, Baco Raton, 1994 (in press).

6 R.D. Sekura, K. Sato, H.J. Cahnmann, J. Robbins and W.B. Jakoby, Sulfate transfer to thyroid hormones and their analogs by hepatic aryl sulfotransferase, Endocrinology 108 (1981) 454-456.

7 W.F. Young, C.A. Gorman and R.M. Weinshilboum, Triiodothyronine: a substrate for the thermostable and thermolabile forms of human phenol sulfotransferase, Endocrinology, 122 (1988) 1816-1824.

8 D.W. Gong, N. Murayama, Y. Yamazoe and R. Kato, Hepatic triiodothyronine sulfation and its regulation by growth hormone and triiodothyronine in rats, J. Biochem., 112 (1992) 112-116.

9 R.E. Hurd, F. Santini, P. Naim, B. Lee and I.J. Chopra, A study of triiodothyronine sulfation activity in rat tissues, Clin. Res., 41 (1993) 62A.

10 M.J. Berry and P.R. Larsen, The role of selenium in thyroid hormone action, Endocrinol. Rev., 13 (1992) 207-219.

11 J.A. Mol and T.J. Visser, Rapid and selective inner ring deiodination of thyroxine sulfate, Endocrinology, 117 (1985) 8-12.

12 T.J. Visser, J.A. Mol and M.H. Otten, Rapid deiodination of triiodothyronine sulfate by rat liver microsomal fraction, Endocrinology, 112 (1983) 1547-1549.

13 T.J. Visser, E. Kaptein, O.T. Terpstra and E.P. Krenning, Deiodination of thyroid hormone by human liver, J. Clin. Endocrinol. Metab., 67 (1988) 17-24.

14 T.J. Visser, D. Fekkes, R. Docter and G. Hennemann, Kinetics of enzymic reductive deiodination of iodothyronines, Biochem. J., 179 (1979) 489-495.

15 M.H. Otten, J.A. Mol and T.J. Visser, Sulfation preceding deiodination of iodothyronines in rat hepatocytes, Science, 221 (1983) 81-83.

16 M.J. Berry, L. Banu and P.R. Larsen, Type I iodothyronine deiodinase is a selenocysteinecontaining enzyme, Nature, 349 (1991) 438-440. 
17 S.J. Mandel, M.J. Berry, J.D. Kieffer, J.W. Harney, R.L. Warne and P.R. Larsen, Cloning and in vitro expression of the human selenoprotein, type I iodothyronine deiodinase, J. Clin. Endocrinol. Metab., 75 (1992) 1133-1139.

18 M. Rutgers, F.A. Heusdens and T.J. Visser, Deiodination of iodothyronine sulfamates by rat liver microsomes, Endocrinology, 129 (1991) 1375-1381.

19 S.J. Eelkman Rooda, M.H. Otten, M.A.C. van Loon, E. Kaptein and T.J. Visser, Metabolism of $\mathrm{T}_{3}$ by rat hepatocytes, Endocrinology 125 (1989) 2187-2197.

20 F. Santini, R.E. Hurd and I.J. Chopra, A study of metabolism of deaminated and sulfoconjugated jodothyronines by rat placental iodothyronine 5-monodeiodinase, Endocrinology, 131 (1992) 1689-1694.

21 F. Santini, I.J. Chopra, S.Y. Wu, D.H. Solomon and G.N. Chua Teco, Metabolism of 3,5,3'triiodothyronine sulfate by tissues of the fetal rat: a consideration of the role of desulfation of $3,5,3^{\prime}$ triiodothyronine sulfate as a source of $T_{3}$, Pediat. Res., 31 (1992) 541-544.

22 S.J. Eelkman Rooda, M.A.C. van Loon, F. Bonthuis, F.A. Heusdens, E. Kaptein E and T.J. Visser, Effects of iopanoic acid on the metabolism of $\mathrm{T}_{3}$ in rats, Ann. Endocrinol., 49 (1988) 182.

23 W.W. de Herder, F. Bonthuis, M. Rutgers, M.H. Otten, M.P. Hazenberg and T.J. Visser, Effects of inhibition of type I iodothyronine deiodinase and phenol sulfotransferase on the biliary clearance of triiodothyronine in rats, Endocrinology 122 (1988) 153-157.

24 M. Rutgers, F. Bonthuis, W.W. de Herder and T.J. Visser, Accumulation of plasma triiodothyronine sulfate in rats treated with propylthiouracil, J. Clin. Invest., 80 (1987) 758-762.

25 S.J. Eelkman Rooda, E. Kaptein, M.A.C. van Loon and T.J. Visser, Development of a radioimmunoassay for triiodothyronine sulfate, J. Immunoassay, 9 (1988) 125-134.

26 S.J. Eelkman Rooda, E. Kaptein, M. Rutgers and T.J. Visser, Increased plasma 3,5,3'. triiodothyronine sulfate in rats with inhibited type I iodothyronine deiodinase activity, as measured by radioimmunoassay, Endocrinology, 124 (1989) 740-745.

27 S.J. Eelkman Rooda, E. Kaptein and T.J. Visser, Serum triiodothyronine sulfate in man measured by radioimmunoassay, J. Clin. Endocrinol. Metab., 69 (1989) 552-556.

28 J.S. LoPresti, L. Mizuno, A. Nimalysuria, K.P. Anderson, C.A. Spencer and J.T. Nicoloff, Characteristics of 3,5,3'-triiodothyronine sulfate metabolism in euthyroid man, J. Clin. Endocrinol. Metab., 73 (1991) 703-709.

29 I.J. Chopra, S.Y. Wu, G.N. Chua Teco and F. Santini, A radioimmunoassay of 3,5,3'triiodothyronine sulfate: studies in thyroidal and nonthyroidal diseases, pregnancy, and neonatal life, J. Clin. Endocrinol. Metab., 75 (1992) 189-194.

30 S.Y. Wu, D. Polk, S. Wong, A. Reviczky, R. Vu and D.A. Fisher, Thyroxine sulfate is a major thyroid hormone metabolite and a potential intermediate in the monodeiodination pathways in fetal sheep, Endocrinology, 131 (1992) 1751-1756.

31 K. Sato and J. Robbins, Thyroid hormone metabolism in primary cultured rat hepatocytes; effects of glucose, glucagon and insulin, J. Clin. Invest., 68 (1981) 475-483.

32 M. Rutgers, I.G.A.J. Pigmans, F. Bonthuis, R. Docter and T.J. Visser, Effects of propylthiouracil on the biliary clearance of thyroxine $\left(\mathrm{T}_{4}\right)$ in rats: decreased excretion of $3,5,3^{\prime}$-triiodothyronine glucuronide and increased excretion of $3,3^{\prime}, 5^{\prime}$-triiodothyronine glucuronide and $T_{4}$ sulfate, Endocrinology, 125 (1989) 2175-2186.

33 S.Y. Wu, W.S. Huang, D. Polk, W.H. Florsheim, W.L. Green and D.A. Fisher, Identification of thyroxine sulfate $\left(T_{4} S\right)$ in human serum and amniotic fluid by a novel $T_{4} S$ radioimmunoassay, Thyroid, 2 (1992) 101-105.

34 I.J. Chopra, F. Santini, R.E. Hurd and G.N. Chua Teco, A radioimmunoassay for measurement of thyroxine sulfate, J. Clin. Endocrinol. Metab., 76 (1993) 145-150.

35 S.J. Eelkman Rooda, M.A.C. van Loon and T.J. Visser, Metabolism of reverse triiodothyronine by isolated rat hepatocytes, J. Clin. Invest. 79 (1987) 1740-1748.

36 S.Y. Wu, W.S. Huang, D. Polk, W.L. Chen, A. Reviczky, J. Williams, I.J. Chopra and D.A. Fisher, The development of a radioimmunoassay for reverse triiodothyronine sulfate in human serum and amniotic fluid, J. Clin. Endocrinol. Metab., 76 (1993) 1625-1630.

37 S.Y. Wu, D.H. Polk, W.S. Huang, A. Reviczky, K. Wang and D.A. Fisher, Sulfate conjugates of iodothyronines in developing sheep; effect of fetal hypothyroidism, Am. J. Physiol., 265 (1993) E115-E120. 
38 S.W. Spaulding, T.J. Smith, P.M. Hinkle, F. B. Davis, M.P. Kung and J.A. Roth, Studies of the biological activity of triiodothyronine sulfate, J. Clin. Endocrinol. Metab., 74 (1992) 1062-1067.

39 M.E. Everts, R. Docter, E.P. Krenning, T.J. Visser and G. Hennemann, Uptake of $\mathrm{T}_{3} \mathrm{~S}$ and suppression of TSH secretion in cultured rat anterior pituitary cells, Program of the 75th Annual Meeting of the Endocrine Society, Las Vegas, 1993, abstract 825.

40 M.P. Hazenberg, W.W. de Herder and T.J. Visser, Hydrolysis of iodothyronine conjugates by intestinal bacteria, FEMS Microbiol. Rev., 54 (1988) 9-16.

41 W.W de Herder, M.P. Hazenberg, A.M. Pennock-Schröder, A.C. Oosterlaken, M. Rutgers and T.J. Visser, On the enterohepatic cycle of triiodothyronine in rats: importance of the intestinal microflora, Life Sci., 45 (1989) 849-856.

42 M. Rutgers, F.A. Heusdens, F. Bonthuis, W.W. de Herder, M.P. Hazenberg and T.J. Visser, Enterohepatic circulation of triiodothyronine $\left(T_{3}\right)$ in rats: importance of the microflora for the liberation and reabsorption of $T_{3}$ from biliary $T_{3}$ conjugates, Endocrinology, 125 (1989) 2822-2830.

43 M.P. Kung, S.W. Spaulding and J.A. Roth, Desulfation of 3,5,3'-triiodothyronine sulfate by microsomes from human and rat tissues, Endocrinology, 122 (1988) 1195-1200.

44 F. Santini, R.E. Hurd, B. Lee and I.J. Chopra, Thyromimetic effects of 3,5,3'-triiodothyronine sulfate in hypothyroid rats, Endocrinology, 133 (1993) 105-110. 